\title{
Changing equipoise in the landscape of radiation for oligometastatic lung cancer
}

\author{
Samuel R. Schroeder ${ }^{1 \#}$, Michael Leenders ${ }^{2 \#}$, Puneeth Iyengar ${ }^{1}$, Dirk de Ruysscher ${ }^{2}$ \\ ${ }^{1}$ Department of Radiation Oncology, Harold C. Simmons Comprehensive Cancer Center at the University of Texas Southwestern Medical Center, \\ Dallas, TX, USA; ${ }^{2}$ Department of Radiation Oncology (MAASTRO Clinic), GROW-School for Oncology and Developmental Biology, Maastricht \\ University Medical Centre, Maastricht, The Netherlands \\ Contributions: (I) Conception and design: All authors; (II) Administrative support: P Iyengar, D de Ruysscher; (III) Provision of study materials or \\ patients: All authors; (IV) Collection and assembly of data: All authors; (V) Data analysis and interpretation: All authors; (VI) Manuscript writing: All \\ authors; (VII) Final approval of manuscript: All authors. \\ \#These authors contributed equally to this work. \\ Correspondence to: Dirk de Ruysscher. Department of Radiation Oncology (MAASTRO Clinic), GROW-School for Oncology and Developmental \\ Biology, Maastricht University Medical Centre, Maastricht, The Netherlands. Email: dirk.deruysscher@maastro.nl; Puneeth Iyengar. Department of \\ Radiation Oncology, Harold C. Simmons Comprehensive Cancer Center at the University of Texas Southwestern Medical Center, Dallas, TX, USA. \\ Email: puneeth.iyengar@utsouthwestern.edu.
}

\begin{abstract}
There is growing interest in exploring use of local therapies in the management of oligometastatic non-small cell lung cancer (NSCLC) to provide durable local and distant disease control. Prospective phase II studies have incorporated local therapy (predominantly stereotactic ablative radiotherapy or SABR) to both primary and metastatic sites. For patients who received these treatments, median progression-free survival (PFS) and overall survival (OS) exceeded that of historical controls treated with systemic therapy alone (9.7-23.5 and 13.5-41.2 months, respectively). Additionally, three trials randomized oligometastatic NSCLC patients to standard of care systemic therapy regimens $v s$. local consolidative therapy (LCT) plus standard of care systemic therapy (or observation) and all demonstrated a significant improvement in PFS, with two showing OS benefits to date. Notably, a majority of these trials selected patients with at least stable disease after completion of systemic therapy for local therapy and defined the oligometastatic state as one with no more than five metastatic sites spread across three organs. For patients with oligometastatic NSCLC, there are many important factors that should drive use and timing of local therapy, including metastatic presentation sequence (synchronous vs. metachronous), extent of disease (number and distribution of sites), and quality of life goals. The referenced clinical trials accrued patients prior to the approval of immunotherapy for metastatic NSCLC, so the benefits of any local therapy in this setting remain uncertain. To ultimately clarify the role of local therapy in oligometastatic NSCLC in the era of improving systemic therapy efficacy (i.e., immunotherapy and targeted therapy combinations with cytotoxics), we recommend enrollment in in phase III studies with OS endpoints (i.e., NRG LU 002 and SARON) whenever possible. These and other important issues associated with local therapy for oligometastatic NSCLC are reviewed in this paper.
\end{abstract}

Keywords: Lung cancer; non-small cell lung cancer (NSCLC); radiation; oligometastases; stereotactic body radiotherapy (SBRT); stereotactic ablative radiotherapy (SABR)

Submitted Jun 08, 2019. Accepted for publication Jul 24, 2019.

doi: $10.21037 /$ tlcr.2019.07.09

View this article at: http://dx.doi.org/10.21037/tlcr.2019.07.09 


\section{Introduction}

For both men and women, metastatic non-small cell lung cancer (NSCLC) represents the greatest contributor to cancer related mortality (1). Despite advances in screening, nearly half of newly diagnosed NSCLC will be metastatic at presentation (2). Furthermore, approximately half of patients with locally advanced NSCLC will progress distantly despite aggressive treatment with definitive chemoradiation or neoadjuvant chemoradiation followed by surgery $(3,4)$. Recently, incorporation of adjuvant durvalumab after definitive chemoradiation for locally advanced NSCLC was found to decrease the incidence of new site progression to $22.5 \%$ compared to $33.8 \%$ in the control arm (5). Thus, even with contemporary treatment approaches, many patients who initially present with localized disease will ultimately progress.

Historically, synchronous and metachronous metastatic NSCLC were considered incurable and staging did not distinguish solitary or limited metastatic involvement from diffuse disseminated disease (6). However, investigators began to recognize patients with low volumes of metastatic involvement to challenge the concept of incurable metastatic NSCLC. The principle of oligometastases was well popularized in 1995 by Hellman and Weichselbaum who hypothesized that metastatic disease occurs in a stepwise manner, initially with limited metastases followed by progression to widespread disease $(7,8)$. With improvements in imaging, including positron emission tomography/ computed tomography (PET/CT) and magnetic resonance imaging (MRI), identification of isolated and small metastatic deposits is accomplished with higher sensitivity and specificity. Thus, modern imaging can identify patients in oligometastatic state who may be amenable to potentially curative local therapy. This concept is applicable both for synchronous as well as for metachronous metastatic NSCLC. Both states are anatomically and biologically heterogeneous, but in metachronous metastatic disease, on top of this, the time between the primary treatment and the occurrence of metastases also influences largely the survival (9). The time interval is determined by the biological aggressiveness. Oligo-progressive disease is a distinct entity of patients with metastatic disease in which one or a few metastatic sites show progressive disease, while other metastases remain controlled while receiving systemic therapy.

\section{Definition of oligometastases}

There is no consensus on the definition of oligometastases in literature. The European Society for Medical Oncology (ESMO) and the National Comprehensive Cancer Network (NCCN) guidelines and the $8^{\text {th }}$ edition of the TNM staging all use another definition of what oligometastases are (10-12). Completed and currently accruing studies use widely different definitions, which will probably have consequences for prognosis and treatment.

In an attempt to come to a consensus definition, which would aid the development of clinical trials, the European Organization for Research and Treatment of Cancer (EORTC) Lung Cancer Group organized a consensus meeting (13). It was proposed that oligometastases are defined as a maximum of five metastases and three organs. Mediastinal lymph node involvement was not counted as a metastatic site. An 18-fluorodeoxyglucose-PET $\left({ }^{18} \mathrm{FDG}\right.$ PET/CT) and brain imaging were considered mandatory. A dedicated liver MRI was advised for a solitary liver metastasis, and thoracoscopy and biopsies of distant ipsilateral pleural sites for a solitary pleural metastasis. For mediastinal staging, an ${ }^{18} \mathrm{FDG}$ PET/CT was considered the minimum requirement, with pathological confirmation recommended if this influences the treatment strategy. Biopsy of a solitary metastatic location is mandated unless the multidisciplinary team is of the opinion that the risks outweigh the benefits.

\section{Prospective evidence for local therapy in oligometastatic NSCLC}

Given the strong suggestion of a benefit for local treatment in carefully selected oligometastatic NSCLC patients $(14,15)$, there are multiple prospective trials evaluating a variety of therapeutic approaches. Theoretically, all combinations and sequencing of any systemic treatment with any radical radiotherapy and/or surgery could be envisaged.

In a trial performed by De Ruysscher and colleagues, patients with fewer than five sites of metastatic disease were enrolled to a prospective phase II trial of local therapy (Table 1). Both surgical and radiotherapy was allowed for the treatment of metastatic sites and previous response to systemic treatment was not required. Of 39 evaluable patients, $87 \%$ had a solitary metastatic site and $95 \%$ of patients received chemotherapy as part of their treatment regimen (systemic therapy was not mandatory per protocol). Metastatic sites were treated with a mixture of surgical resection, conventional radiation (bone metastases, adjuvant whole brain radiotherapy), and stereotactic radiosurgery 
Table 1 Completed studies

\begin{tabular}{|c|c|c|c|c|c|}
\hline $\begin{array}{l}\text { Study } \\
\text { authors }\end{array}$ & Study design & $\begin{array}{l}\text { Treatment } \\
\text { setting }\end{array}$ & Patient eligibility & Study arm(s) & Results \\
\hline $\begin{array}{l}\text { De } \\
\text { Ruysscher } \\
\text { et al. }(16,17)\end{array}$ & $\begin{array}{l}\text { Single arm } \\
\text { phase II }\end{array}$ & Consolidation & $\begin{array}{l}\text { Oligometastatic NSCLC }(<5 \\
\text { sites), no response to systemic } \\
\text { therapy required }\end{array}$ & $\begin{array}{l}\text { Chemo with surgery or } \\
\text { radiation for metastatic sites }\end{array}$ & $\begin{array}{l}\text { Median PFS, OS } 12.1 \text { and } \\
13.5 \text { months, respectively }\end{array}$ \\
\hline $\begin{array}{l}\text { Gomez } \\
\text { et al. }(18,19)\end{array}$ & $\begin{array}{l}\text { Randomized } \\
\text { phase II }\end{array}$ & Consolidation & $\begin{array}{l}\text { Oligometastatic NSCLC } \\
\text { ( } \leq 5 \text { sites), EGFR mutations } \\
\text { allowed ( } 12 \% \text { of patients) }\end{array}$ & $\begin{array}{l}\text { Systemic therapy followed } \\
\text { by local consolidative } \\
\text { therapy (SABR, surgery, } \\
\text { or chemoradiation) vs. } \\
\text { maintenance treatment alone }\end{array}$ & $\begin{array}{l}\text { Median PFS } 14.2 \text { vs. } \\
4.4 \text { months; OS } 41.2 \text { vs. } \\
17 \text { months }\end{array}$ \\
\hline $\begin{array}{l}\text { lyengar } \\
\text { et al. (20) }\end{array}$ & $\begin{array}{l}\text { Randomized } \\
\text { phase II }\end{array}$ & Consolidation & $\begin{array}{l}\text { Oligometastatic NSCLC } \\
\text { ( } \leq 6 \text { sites including primary) }\end{array}$ & $\begin{array}{l}\text { Chemo followed by SABR vs. } \\
\text { maintenance treatment alone }\end{array}$ & $\begin{array}{l}\text { Median PFS } 9.7 \text { vs. } \\
3.5 \text { months }\end{array}$ \\
\hline $\begin{array}{l}\text { Arrieta } \\
\text { et al. (23) }\end{array}$ & $\begin{array}{l}\text { Single arm } \\
\text { phase II }\end{array}$ & Consolidation & $\begin{array}{l}\text { Oligometastatic NSCLC } \\
\text { ( } \leq 5 \text { sites), EGFR/ALK } \\
\text { mutations allowed ( } 43 \% \text { of } \\
\text { patients) }\end{array}$ & $\begin{array}{l}\text { Systemic therapy followed by } \\
\text { local consolidative therapy } \\
\text { (conventional RT, SABR, } \\
\text { surgery, chemoradiation, or } \\
\text { RFA) }\end{array}$ & $\begin{array}{l}\text { Median PFS } 23.5 \text { months, } \\
\text { median OS NR; } 51.4 \% \text { of } \\
\text { patients achieved CR by } \\
\text { PET/CT, CR associate with } \\
\text { significantly improved PFS } \\
\text { (NR vs. } 14.3 \text { months) and OS } \\
\text { (NR vs. } 27.4 \text { months) }\end{array}$ \\
\hline $\begin{array}{l}\text { Palma } \\
\text { et al. (24) }\end{array}$ & $\begin{array}{l}\text { Randomized } \\
\text { phase II }\end{array}$ & Consolidation & $\begin{array}{l}\text { Limited metastatic disease } \\
\text { from any primary site ( } \leq 5 \text { sites) }\end{array}$ & $\begin{array}{l}\text { Standard of care plus SABR } \\
\text { vs. standard of care alone }\end{array}$ & $\begin{array}{l}\text { Median PFS } 12 \text { vs. } 6 \text { months; } \\
\text { OS } 41 \text { vs. } 28 \text { months }\end{array}$ \\
\hline
\end{tabular}

PFS, progression-free survival; OS, overall survival; NSCLC, non-small cell lung cancer; SABR, stereotactic ablative radiotherapy; EGFR, epidermal growth factor receptor; ALK, anaplastic lymphoma kinase; CR, complete response; NR, not reached; PET/CT, positron emission tomography/computed tomography.

(intracranial metastases). The median progression-free survival (PFS) and overall survival (OS) were 12.1 and 13.5 months, respectively (16). Long-term results were recently published and 5-year PFS was found to be $8 \%$ (17). This trial is notable in that the vast majority of patients had solitary metastatic disease and local recurrence was uncommon $(7.7 \%)$. However, over $80 \%$ of patients progressed within 2 years, demonstrating the need for effective systemic therapy after local treatment.

There are multiple recent trials examining the role of locally ablative radiation therapy in limited metastatic NSCLC. A randomized phase II trial by Gomez et al. investigated the role of local therapy for patients with three or fewer sites of disease after induction chemotherapy and patients with epidermal growth factor receptor $(E G F R)$ and anaplastic lymphoma kinase $(A L K)$ mutations were allowed to receive targeted therapy on the study $(18,19)$. Patients were randomized in a 1:1 manner to local consolidative therapy (LCT, either stereotactic ablative radiotherapy (SABR), surgery, or chemoradiation) with or without maintenance therapy or to maintenance therapy alone (maintenance observation was allowed for both arms). The trial was stopped early at an interim analysis after 74 patients were enrolled with a median PFS of 14.2 months in the consolidative therapy arm and 4.4 months in the maintenance only arm. An OS benefit of 41.2 vs. 17 months was also recently reported and a subset of patients who received consolidative therapy at the time of progression 
(from either randomization arm) were found to have improved OS of $37.6 \mathrm{vs}$. 9.4 months. In view of the phase II design and the very low number of patients, these results should be regarded as a proof-of-concept, but not as a definitive proof for an OS gain with local ablative therapy.

Iyengar et al. performed a similar randomized phase II trial in which patients with 6 or fewer sites of disease after induction chemotherapy (must have had at least stable disease) were randomized to SABR followed by maintenance chemotherapy or maintenance chemotherapy alone (20). Hypofractionated radiotherapy to the primary tumor and mediastinum was allowed and patients with EGFR or $A L K$ mutations were not eligible. The median PFS was 9.7 months in the SABR plus maintenance chemotherapy arm and 3.5 months in the maintenance alone arm. None of the patients who progressed in the SABR plus maintenance chemotherapy arm progressed at an initial site of disease and treatment dramatically shifted the expected patterns of failure.

Collen and colleagues performed a single-arm phase II trial that was eligible to oligometastatic NSCLC patients with synchronous or metachronous progression and five or fewer metabolically active metastatic sites (21). Both induction chemotherapy and SABR as primary treatment were allowed and no additional systemic therapy was given after radiotherapy until the time of progression. Median PFS and OS were 11.2 and 23 months.

A single-arm phase II trial by Petty et al. enrolled 29 patients with oligometastatic NSCLC defined as no more than five lesions spread across three disease sites other than the primary tumor and mediastinal lymph nodes (22). Enrolled patients received 3-6 cycles of platinum-based chemotherapy followed by treatment to primary and metastatic sites (SABR favored, conventional radiation of 60 Gy in 30 fractions recommended if SABR could not safely be delivered). Similar to Collen et al., no additional systemic therapy was given until the time of progression. Median PFS and OS were 11.2 and 28.4 months, respectively.

Arrieta et al. recently reported results from a single-arm phase II trial where 37 patients with oligometastatic NSCLC ( $\leq 5$ sites) received LCT [conventional radiotherapy, SABR, surgery, chemoradiation, or Radiofrequency ablation (RFA)] after four cycles of systemic therapy (only stable disease and partial response allowed) (23). Notably, EGFR and $A L K$ mutations were allowed and accounted for $43 \%$ of enrolled patients [11 of 16 of mutation-positive patients received tyrosine kinase inhibitor (TKI)'s]. Median PFS and OS were 23.5 months and not reached (NR), respectively. Posttreatment FDG PET/CT was also obtained for all enrolled patients and $51.4 \%$ achieved metabolic complete response (CR), which corresponded to significantly improved PFS (NR vs. 14.3 months) and OS (NR vs. 27.4 months).

Palma and colleagues reported results of the SABRCOMET randomized phase II trial where 99 patients with five or fewer metastatic sites from any primary site were randomized in a 2:1 fashion to standard of care plus SABR or to standard of care alone (24). Patients with primary lung cancer comprised $18 \%$ of each treatment arm (18 patients in total). Notably, the vast majority of patients enrolled had metachronous disease. For all disease sites combined, the median PFS was 12 vs. 6 months in favor of the SABR arm and reached statistical significance. Median OS was $41 v s .28$ months also in favor of the SABR arm but was not statistically significant. There were also three treatment related deaths in the experimental arm.

There is also interest in providing consolidative therapy to metastatic NSCLC patients who have limited sites of progressive disease, so-called oligoprogressive disease. In a prospective single arm phase II study patients with $<$ six sites of extra-cranial progression who had progressed on at least one line of chemotherapy were treated with SABR and maintenance erlotinib (25). Of note, the study was performed prior to the indication for erlotinib therapy being limited to patients with known EGFR mutations and thus the mutation status was not checked on all patients enrolled (13/24 patients had EGFR status available and were all wild-type). A change in the pattern of relapse was noted, with a shift in failure from treated sites of known disease to new sites of distant failure. By treating new sites of progression with SABR, several patients in this study were able to remain on erlotinib for additional periods of 6 to 9 months. The median PFS and OS for patients in the study were 14.7 and 20.4 months, respectively. The currently enrolling STOP (NCT02756793) and HALT (NCT03256981) trials are randomized trials evaluating the role of locally ablative therapy on PFS in patients with oligoprogressive NSCLC (Table 2).

The management of solitary/limited central nervous system (CNS) involvement in metastatic NSCLC is beyond the scope of this review and has been discussed thoroughly elsewhere (26). Collectively, these studies suggest there is a benefit with targeted agents when appropriate and/ or aggressive local therapy in the treatment of brain metastases. 
Table 2 Currently accruing phase III trials

\begin{tabular}{|c|c|c|c|c|c|}
\hline Trial & Initiation year & Study design & Patient eligibility & Study arms & Primary endpoint \\
\hline $\begin{array}{l}\text { SARON } \\
\text { NCT02417662 }\end{array}$ & 2016 & $\begin{array}{l}\text { Randomized } \\
\text { phase III }\end{array}$ & $\begin{array}{l}\text { Oligometastatic NSCLC ( } \leq 3 \text { sites), } \\
\text { eligible to receive chemotherapy }\end{array}$ & $\begin{array}{l}\text { Chemotherapy plus SABR vs. } \\
\text { chemotherapy alone }\end{array}$ & OS \\
\hline $\begin{array}{l}\text { HALT } \\
\text { NCT03256981 }\end{array}$ & 2017 & $\begin{array}{l}\text { Randomized } \\
\text { phase II/III }\end{array}$ & $\begin{array}{l}\text { Advanced NSCLC with actionable } \\
\text { mutation and confirmed response } \\
\text { to TKI treatment with } \leq 3 \text { sites of } \\
\text { progression }\end{array}$ & $\begin{array}{l}\text { Maintenance TKI plus SABR } \\
\text { vs. maintenance TKI alone }\end{array}$ & PFS \\
\hline
\end{tabular}

PFS, progression-free survival; OS, overall survival; NSCLC, non-small cell lung cancer; SABR, stereotactic ablative radiotherapy; TKI, tyrosine kinase inhibitor.

\section{Combining immunotherapy and SABR}

It is important to note that the above studies accrued patients before immunotherapy was approved and routinely used as either monotherapy or combination treatment with platinum-based chemotherapy in the first-line setting. A recently reported single-arm phase II study by Bauml et al. enrolled 45 patients with oligometastatic NSCLC (up to four sites) and administered ablative treatment (SABR, chemoradiation, or surgery) prior to receiving pembrolizumab (27). Patients with both synchronous (12 patients) and metachronous (33 patients) metastases were eligible for enrollment. Median PFS was 25 months for all-comers (16.9 months and NR for metachronous and synchronous patients, respectively) and median survival was not yet reached.

Most retrospective analyses have identified metachronous patients as a highly select subset that tend to have better outcomes compared to patients with synchronous presentations; thus, this finding with the addition of immunotherapy is interesting and warrants further testing. While preliminary, these data are encouraging as it demonstrates that optimizing systemic and ablative therapies may further improve outcomes.

To confirm results of the trials described above, there are currently two trials underway SARON (NCT02417662) and NRG-LU-002 (NCT03137771), which are powered to detect an OS benefit and will more definitely elucidate the role of locally ablative therapy in the treatment of limited metastatic NSCLC (Table 2).

\section{Patient selection and treatment sequence}

As previously discussed, there is no consensus on the definition of oligometastases, but the EORTC Lung Cancer Group proposed a maximum of five metastases and three organs. Nonetheless, the vast majority of patients included in clinical trials only had 1 or 2 metastatic sites, even though mostly up to five metastases were allowed $(16,18,20-25)$. Even with this selection criterion and the addition of systemic treatment, only a sizable minority (20-25\%) may experience long-term PFS and improved OS when treated with a radical approach (28). The occurrence of new distant metastases is the by far (>90\%) most common site of failure $(18,20)$. Identification of patients who are most likely to achieve favorable outcomes with a radical local therapy is thereby of utmost importance.

In the study of De Ruysscher et al. patients were not selected for a response on systemic treatment, whereas the trials of Gomez et al., Iyengar et al. and Petty et al. required patients to maintain at least stable before beginning a radical local therapy $(16,18,20,22)$. As distant progression is the most important site of failure and response to systemic agents is the most important prognostic factor for PFS and OS in patients with locally advanced and metastatic NSCLC, selection of patients based on response is logical (10).

Moreover, all cited studies only included patients with a good performance status (WHO 0-1), because this is an important prognostic factor for PFS and OS (10). The volume of the primary tumor, volume of the nodes, volume of the metastases, total tumor volume, SUVmax 
of FDG uptake of the primary tumor and of the nonbrain metastases, "local stage", WHO performance status, co-morbidity score, location of metastases, number of metastases, histological type, gender, age and sequential $v s$. concurrent chemo-radiotherapy were not associated with OS or PFS in the study of De Ruysscher et al., which may be due to the small numbers of patients $(n=39)(17)$. In contrast, Ashworth et al., based on an individual patient data meta-analysis containing 757 patients, identified the following factors being associated with OS: synchronous versus metachronous metastases, $\mathrm{N}$-stage, and adenocarcinoma histology (14). A model was made with three risk groups; (I) low-risk, metachronous metastases (5-year OS, 47.8\%), (II) intermediate risk, synchronous and N0 disease (5-years OS, 36.2\%) and (III) high risk, synchronous and N1/N2 disease (5-year OS, 13.8\%).

To relate molecular characteristics of the tumor with prognosis, Lussier et al. examined 63 oligometastatic (1-5 sites) patients who underwent (partial-) lung resection for metastases and radical treatment to all metastatic sites. The study showed that there was a different expression of microRNA between low rate of progression and high rate of progression. They concluded that oligo- and polymetastasis are distinct entities at the clinical and molecular level (29).

Patient selection based on response to systemic therapy may be challenged in the era of immunotherapy. The above described trial of Bauml et al. showed promising results and support the combination of immunotherapy with radiotherapy $(30,31)$. The abscopal effect is an interesting phenomenon regarding the previous described combination and could play a clinical role in the future (32). Many ongoing trials investigate the optimal strategy for patients with oligometastatic disease.

\section{Conclusions}

Patients with oligometastatic NSCLC are a special group in stage IV NSCLC. The recent consensus for defining these patients may facilitate clinical research. As distant metastatic recurrence remains the single most important site of failure, better strategies to optimally integrate radical local therapy with systemic treatments are mandatory. The combination of SABR with immunotherapy is promising. At present, optimal selection of patients include response on induction chemotherapy or targeted agents and a good performance status (WHO 0-1).

\section{Acknowledgments}

None.

\section{Footnote}

Conflicts of Interest: D de Ruysscher: Advisory board: Merck Serono/Pfizer, Bristol-Meyers-Squibb, Roch/Genentech, Celgene, Astra Zeneca. Research Support: BristolMeyers-Squibb, Astra Zeneca, Philips, Olink. All fees to the institution (not personal). The other authors have no conflicts of interest to declare.

Ethical Statement: The authors are accountable for all aspects of the work in ensuring that questions related to the accuracy or integrity of any part of the work are appropriately investigated and resolved.

\section{References}

1. Wong MCS, Lao XQ, Ho KF, et al. Incidence and mortality of lung cancer: global trends and association with socioeconomic status. Sci Rep 2017;7:14300.

2. Rusch VW, Rice TW, Crowley J, et al. The seventh edition of the American Joint Committee on Cancer/ International Union Against Cancer Staging Manuals: the new era of data-driven revisions. J Thorac Cardiovasc Surg 2010;139:819-21.

3. Bradley JD, Paulus R, Komaki R, et al. Standarddose versus high-dose conformal radiotherapy with concurrent and consolidation carboplatin plus paclitaxel with or without cetuximab for patients with stage IIIA or IIIB non-small-cell lung cancer (RTOG 0617): a randomised, two-by-two factorial phase 3 study. Lancet Oncol 2015;16:187-99.

4. Albain KS, Swann RS, Rusch VW, et al. Radiotherapy plus chemotherapy with or without surgical resection for stage III non-small-cell lung cancer: a phase III randomised controlled trial. Lancet 2009;374:379-86.

5. Antonia SJ, Villegas A, Daniel D, et al. Overall Survival with Durvalumab after Chemoradiotherapy in Stage III NSCLC. N Engl J Med 2018;379:2342-50.

6. Postmus PE, Kerr KM, Oudkerk M, et al. Early and locally advanced non-small-cell lung cancer (NSCLC): ESMO Clinical Practice Guidelines for diagnosis, treatment and follow-up. Ann Oncol 2017;28:iv1-21.

7. Weichselbaum RR, Hellman S. Oligometastases revisited. 
Nat Rev Clin Oncol 2011;8:378-82.

8. Hellman S, Weichselbaum RR. Oligometastases. J Clin Oncol 1995;13:8-10.

9. Swanton C. Intratumor Heterogeneity: Evolution through Space and Time. Cancer Research 2012;72:4875-82.

10. Planchard D, Popat S, Kerr K, et al. Metastatic non-small cell lung cancer: ESMO Clinical Practice Guidelines for diagnosis, treatment and follow-up. Ann Oncol 2018;29:iv192-iv237.

11. Detterbeck FC, Boffa DJ, Kim AW, et al. The Eighth Edition Lung Cancer Stage Classification. Chest 2017;151:193-203.

12. Ettinger DS, Aisner DL, Wood DE, et al. NCCN Guidelines Insights: Non-Small Cell Lung Cancer, Version 5.2018. J Natl Compr Canc Netw 2018;16:807-21.

13. Dingemans A, Hendriks L, Berghmans T, et al. MA25.02 Searching for a Definition of Synchronous Oligometastatic (sOMD)-NSCLC: A Consensus from Thoracic Oncology Experts. J Thorac Oncol 2018;13:S446.

14. Ashworth AB, Senan S, Palma DA, et al. An individual patient data metaanalysis of outcomes and prognostic factors after treatment of oligometastatic non-small-cell lung cancer. Clin Lung Cancer 2014;15:346-55.

15. Congedo MT, Cesario A, Lococo F, et al. Surgery for oligometastatic non-small cell lung cancer: longterm results from a single center experience. J Thorac Cardiovasc Surg 2012;144:444-52.

16. De Ruysscher D, Wanders R, van Baardwijk A, et al. Radical treatment of non-small-cell lung cancer patients with synchronous oligometastases: long-term results of a prospective phase II trial (Nct01282450). J Thorac Oncol 2012;7:1547-55.

17. De Ruysscher D, Wanders R, Hendriks LE, et al. Progression-Free Survival and Overall Survival Beyond 5 Years of NSCLC Patients With Synchronous Oligometastases Treated in a Prospective Phase II Trial (NCT 01282450). J Thorac Oncol 2018;13:1958-61.

18. Gomez DR, Blumenschein GR Jr, Lee JJ, et al. Local consolidative therapy versus maintenance therapy or observation for patients with oligometastatic non-smallcell lung cancer without progression after first-line systemic therapy: a multicentre, randomised, controlled, phase 2 study. Lancet Oncol 2016;17:1672-82.

19. Gomez DR, Tang C, Zhang J, et al. Local Consolidative Therapy Vs. Maintenance Therapy or Observation for Patients With Oligometastatic Non-Small-Cell Lung Cancer: Long-Term Results of a Multi-Institutional, Phase
II, Randomized Study. J Clin Oncol 2019;37:1558-65.

20. Iyengar P, Wardak Z, Gerber DE, et al. Consolidative Radiotherapy for Limited Metastatic Non-Small-Cell Lung Cancer: A Phase 2 Randomized Clinical Trial. JAMA Oncol 2018;4:e173501.

21. Collen C, Christian N, Schallier D, et al. Phase II study of stereotactic body radiotherapy to primary tumor and metastatic locations in oligometastatic nonsmall-cell lung cancer patients. Ann Oncol 2014;25:1954-9.

22. Petty WJ, Urbanic JJ, Ahmed T, et al. Long-Term Outcomes of a Phase 2 Trial of Chemotherapy With Consolidative Radiation Therapy for Oligometastatic Non-Small Cell Lung Cancer. Int J Radiat Oncol Biol Phys 2018;102:527-35.

23. Arrieta O, Barrón F, Maldonado F, et al. Radical consolidative treatment provides a clinical benefit and long-term survival in patients with synchronous oligometastatic non-small cell lung cancer: A phase II study. Lung Cancer 2019;130:67-75.

24. Palma DA, Olson R, Harrow S, et al. Stereotactic ablative radiotherapy versus standard of care palliative treatment in patients with oligometastatic cancers (SABRCOMET): a randomised, phase 2, open-label trial. Lancet 2019;393:2051-8.

25. Iyengar P, Kavanagh BD, Wardak Z, et al. Phase II trial of stereotactic body radiation therapy combined with erlotinib for patients with limited but progressive metastatic non-small-cell lung cancer. J Clin Oncol 2014;32:3824-30.

26. Preusser M, Winkler F, Valiente $M$, et al. Recent advances in the biology and treatment of brain metastases of nonsmall cell lung cancer: summary of a multidisciplinary roundtable discussion. ESMO Open 2018;3:e000262.

27. Bauml J, Mick R, Ciunci C, et al. OA07.01 Phase II Study of Pembrolizumab for Oligometastatic Non-Small Cell Lung Cancer (NSCLC) Following Completion of Locally Ablative Therapy (LAT). J Thorac Oncol 2018;13:S335-6.

28. Stephens SJ, Moravan MJ, Salama JK. Managing Patients With Oligometastatic Non-Small-Cell Lung Cancer. J Oncol Pract 2018;14:23-31.

29. Lussier YA, Khodarev NN, Regan K, et al. Oligo- and Polymetastatic Progression in Lung Metastasis(es) Patients Is Associated with Specific MicroRNAs. PLoS One 2012;7:e50141.

30. Van Limbergen EJ, De Ruysscher DK, Olivo Pimentel $\mathrm{V}$, et al. Combining radiotherapy with immunotherapy: 
the past, the present and the future. Br J Radiol 2017;90:20170157.

31. Formenti SC, Demaria S. Systemic effects of local radiotherapy. Lancet Oncol 2009;10:718-26.

Cite this article as: Schroeder SR, Leenders M, Iyengar P, de Ruysscher D. Changing equipoise in the landscape of radiation for oligometastatic lung cancer. Transl Lung Cancer Res 2019;8(Suppl 2):S184-S191. doi: 10.21037/tlcr.2019.07.09
32. Reynders K, Illidge T, Siva S, et al. The abscopal effect of local radiotherapy: using immunotherapy to make a rare event clinically relevant. Cancer Treat Rev 2015;41:503-10. 